\title{
Effect of first trimester maternal serum pregnancy associated plasma protein: a level on fetomaternal outcome
}

\author{
Shilpi Singh*, Pushpa Singh
}

Department of Obstetrics and Gynecology, RML Hospital, New Delhi, India

Received: 25 August 2019

Revised: 19 November 2019

Accepted: 05 December 2019

\author{
*Correspondence: \\ Dr. Shilpi Singh, \\ E-mail: Shilpisingh20101.ss@ gmail.com
}

Copyright: () the author(s), publisher and licensee Medip Academy. This is an open-access article distributed under the terms of the Creative Commons Attribution Non-Commercial License, which permits unrestricted non-commercial use, distribution, and reproduction in any medium, provided the original work is properly cited.

\begin{abstract}
Background: Serum pregnancy-associated plasma protein-A (PAPP-A) levels fluctuate in continuation with the pregnancy and thus become an important standalone marker in monitoring the adverse outcomes that may occur in pregnancy.

Methods: A prospective observational study was conducted in the department of obstetrics and gynaecology. A total of 240 pregnant women in their first trimester were included in the study. Serum PAPP-A levels were measured at 11$13+6$ week of gestation and were evaluated with respect to the feto-maternal outcome. The data was entered in MS excel spreadsheet and analysis was done using Statistical Package for Social Sciences (SPSS) version 21.0.

Results: The mean age of the study population was 27 years. Among the maternal pregnancy parameters, PIH, preterm labor and Emergency LSCS were significantly associated with low $(<0.5 \mathrm{MoM})$ Serum PAPP-A levels, $\mathrm{P}<0.05$. All the fetal outcome measures: IUGR, IUD, low birth weight, SGA babies, prematurity and NICU admissions, were significantly associated with low $(<0.5 \mathrm{MoM})$ Serum PAPP-A levels, $\mathrm{p}<0.05$.

Conclusions: Serum PAPP-A in the early pregnancy showed significant correlation with feto-maternal outcome. Thus, it has the potential to be used as a prognostic factor and in the management of adverse outcomes by increasing surveillance for pregnant women with high-risk factors.
\end{abstract}

Keywords: Early pregnancy, Feto-maternal outcome, Pregnancy-associated plasma protein-A, Prognostic marker

\section{INTRODUCTION}

Pregnancy-associated plasma protein-A (PAPP-A), a large glycoprotein, is proteolytic in nature. In the very start of pregnancy, it causes activation of insulin-like growth factor (IGF-1) which causes local proliferative processes such as trophoblastic invasion leading to vascularization and early development of placenta. ${ }^{1}$

It has many other functions such as -Prevention of recognition of the fetus by the maternal immune system, matrix mineralization, wound healing, bone remodeling, and angiogenesis. ${ }^{2}$ Thus, its role is very crucial in the early development of fetus, placenta and outcome of pregnancy. Decreased level of PAPP-A during 1st trimester can lead to adverse feto-maternal outcomes such as late abortions, IUGR, preterm delivery, preeclampsia, and stillbirth. ${ }^{3}$

Although its role in conjunction with free serum beta HCG and fetal nuchal translucency has been well established in the 1st trimester screening of chromosomal abnormality but its significance as an individual predictor for adverse outcomes associated with pregnancy like 
early abortion stillbirth, intrauterine uterine growth retardation (IUGR), gestational diabetes mellitus (GDM), intrauterine death (IUD), preterm delivery, Pregnancyinduced hypertension (PIH) is still being studies. Morris RK et al, reviewed 32 studies and concluded that first trimester low maternal serum PAPP-A is associated with adverse pregnancy outcomes, but predictive values are poor and further work should be done to address PAPP-A as an adverse prognostic marker. ${ }^{4}$

In India and worldwide, high literacy and assisted reproductive technology (ART) especially among urban women is contributing a lot in starting late family life. Therefore, if PAPPA, as an individual marker, can be established as a predictor for such adverse outcomes, preventive steps could be taken to either rectify or modify the course of the disease well in time for the better fetomaternal outcome.

Thus, this study was conducted to correlate the levels of PAPP-A in early pregnancy with the maternal and fetal outcome so that it can act as an indicator to start preventive measures at the earliest.

\section{METHODS}

The prospective observational study was conducted in the department of obstetrics and gynecology, at a tertiary hospital, New Delhi, from November 2017 - March 2019. The study was approved by the institutional ethics and review board.

A total of 300 consenting pregnant women, fulfilling inclusion and exclusion criteria were registered for this study, 18 women were lost to follow up, 20 women did not report for sampling and 22 samples were hemolysed. Finally, 240 subjects were followed up throughout pregnancy and labor for the fetomaternal outcome with PAPP-A levels.

\section{Inclusion criteria}

- Pregnant woman in the first trimester

- Age 20-35 years

- Singleton pregnancy

- Dating confirmed.

\section{Exclusion criteria}

- Congenital anomaly

- Family history of chromosomal anomalies

- Known case of chronic diseases (coronary artery disease, chronic kidney disease, type II DM, hypertension, connective tissue disorder and hypothyroidism)

- IVF conception.

A detailed clinical, menstrual, obstetric, past, and family history were taken.

\section{Clinical examination}

General physical and systemic examination was done. All routine antenatal investigations were advised and reviewed.

\section{Estimation of Serum PAPP-A}

- $4 \mathrm{ml}$ of blood was collected through venepuncture and sent to the department of biochemistry, for measuring serum PAPP- A levels

- Samples were centrifuged at $4000 \mathrm{rpm}$ for $5 \mathrm{~min} .22$ samples were hemolysed during centrifugation

- The serum was separated and stored at $-20^{\circ} \mathrm{C}$. PAPPA levels were analyzed in batches of 80 samples using the Chemiluminescence method on Beckman coulter UniCel DxI 600 Analyser by using Access PAPP-A reagent kit

- Auto analyser instantly provided the result of PAPPA levels in $\mathrm{ng} / \mathrm{mL}$ within one hour

- For comparison and statistical analysis individual results were converted into $\mathrm{mIU} / \mathrm{mL}$ and multiple of median (MoM) by using formulae 5

a. $1 \mathrm{ng} / \mathrm{mL}=411 \times 1 \mathrm{mIU} / \mathrm{mL}$

b. $\mathrm{MOM}=$ individual result $(\mathrm{mIU} / \mathrm{mL}) /$ median of study population $\times 2400$

- Results in MoM were recorded in a preformed Performa along with the clinical data of the patient

- 240 Study subjects were followed up throughout pregnancy and during labour

- Correlation of first-trimester maternal serum PAPPA level in MoM and the fetomaternal outcome was observed by suitable methods.

\section{Maternal outcome measures}

- Abortions

- Preterm labor or delivery

- Fetal growth restriction

- Gestational diabetes mellitus (GDM)

- $\quad$ Pregnancy-induced hypertension (PIH)

- $\quad$ Mode of delivery (VD/LSCS)

\section{New-born outcome measures}

- Prematurity Apgar score AGA, SGA, LGA

- IUD

- NICU admission

- Indication and duration of stay.

\section{Statistical analysis}

Categorical variables were presented in number and percentage $(\%)$ and continuous variables were presented as mean \pm SD and median. Normality of data was tested by Kolmogorov-Smirnov test. If the normality was rejected then non parametric test was used. 
Statistical tests were applied as follows

- Quantitative variables were compared using the Independent $t$ test/Mann-Whitney test (when the data sets were not normally distributed) between the two groups and ANOVA/Kruskal Wallis test between three groups

- Qualitative variables were correlated using ChiSquare test/Fisher's exact test. A p-value of $<0.05$ was considered statistically significant.

The data was entered in MS excel spreadsheet and analysis was done using statistical package for social sciences (SPSS) version 21.0.

\section{RESULTS}

Pregnant women included in the study underwent complete clinical evaluation during their OPD visit. serum PAPP-A were measured at $11-13+6$ weeks of gestation. Results of laboratory investigations were recorded and converted in multiple of median (MoM) for study in a preformed proforma.

To study the fetomaternal outcome according to various levels of PAPP-A. It was divided into two groups. At low PAPP-A levels ( $<10$ centile, $<0.5 \mathrm{MoM})$ and normal level (>10 centile, $0.5 \mathrm{MoM})$.

Table 1: Age distribution.

\begin{tabular}{|c|c|c|c|c|}
\hline \multirow{2}{*}{ Age distribution in years } & \multicolumn{2}{|c|}{ Serum PAPP-A levels(MOM) } & \multirow{2}{*}{ Total } & \multirow{2}{*}{ p-value } \\
\hline & $<0.5$ & $>=0.5$ & & \\
\hline $20-25$ years & $5(20.83 \%)$ & $78(36.11 \%)$ & $83(34.58 \%)$ & \multirow{4}{*}{0.227} \\
\hline $26-30$ years & $16(66.67 \%)$ & $105(48.61 \%)$ & $121(50.42 \%)$ & \\
\hline $31-35$ years & $3(12.50 \%)$ & $33(15.28 \%)$ & $36(15.00 \%)$ & \\
\hline Total & $24(100.00 \%)$ & $216(100.00 \%)$ & $240(100.00 \%)$ & \\
\hline
\end{tabular}

Table 2: Association of maternal outcome with serum PAPP-A levels.

\begin{tabular}{|c|c|c|c|c|c|}
\hline \multirow{2}{*}{ Maternal outcome } & & \multicolumn{2}{|c|}{ Serum PAPP-A levels(MOM) } & \multirow[b]{2}{*}{ Total (n) } & \multirow{2}{*}{ p-value } \\
\hline & & $<0.5$ & $>=0.5$ & & \\
\hline \multirow{2}{*}{ PIH } & No & $16(66.67 \%)$ & $199(92.13 \%)$ & 215 & \multirow{2}{*}{0.0001} \\
\hline & Yes & $8(33.33 \%)$ & $17(7.87 \%)$ & 25 & \\
\hline \multirow{2}{*}{ Preterm labor } & No & $20(83.33 \%)$ & $206(95.37 \%)$ & 226 & \multirow{2}{*}{0.039} \\
\hline & Yes & $4(16.67 \%)$ & $10(4.63 \%)$ & 14 & \\
\hline \multirow{2}{*}{ GDM } & No & $23(95.83 \%)$ & $196(90.74 \%)$ & 219 & \multirow{2}{*}{0.704} \\
\hline & Yes & $1(4.17 \%)$ & $20(9.26 \%)$ & 21 & \\
\hline \multirow{4}{*}{ Mode of delivery } & Em LSCS & $7(29.17 \%)$ & $26(12.04 \%)$ & 33 & \multirow{4}{*}{0.017} \\
\hline & Instrumental & $1(4.17 \%)$ & $1(0.46 \%)$ & 2 & \\
\hline & LSCS & $5(20.83 \%)$ & $37(17.13 \%)$ & 42 & \\
\hline & NVD & $11(45.83 \%)$ & $152(70.37 \%)$ & 163 & \\
\hline
\end{tabular}

Table 3: Association of fetal outcome with Serum PAPP-A levels.

\begin{tabular}{|c|c|c|c|c|c|}
\hline \multirow{2}{*}{ Fetal outcome } & & \multicolumn{2}{|c|}{ Serum PAPP-A levels (MOM) } & \multirow{2}{*}{ Total } & \multirow{2}{*}{ p-value } \\
\hline & & $<0.5$ & $>=0.5$ & & \\
\hline \multirow{2}{*}{ IUGR } & No & $21(87.50 \%)$ & $186(86.11 \%)$ & 207 & \multirow[b]{2}{*}{1.000} \\
\hline & Yes & $3(12.50 \%)$ & $30(13.89 \%)$ & 33 & \\
\hline \multirow{2}{*}{ IUD } & No & $21(87.50 \%)$ & $215(99.54 \%)$ & 236 & \multirow{2}{*}{0.003} \\
\hline & Yes & $3(12.50 \%)$ & $1(0.46 \%)$ & 4 & \\
\hline \multirow{2}{*}{ Birth weight (kg) } & $<2.5 \mathrm{~kg}$ & $12(50.00 \%)$ & $54(25.00 \%)$ & 66 & \multirow{2}{*}{0.009} \\
\hline & $>=2.5 \mathrm{~kg}$ & $12(50.00 \%)$ & $162(75.00 \%)$ & 174 & \\
\hline \multirow{4}{*}{ SGA/AGA/LGA } & AGA & $12(50.00 \%)$ & $182(84.26 \%)$ & 194 & \multirow{4}{*}{$<.0001$} \\
\hline & IUD/still birth & $3(12.50 \%)$ & $2(0.93 \%)$ & 5 & \\
\hline & LGA & $1(4.17 \%)$ & $2(0.93 \%)$ & 3 & \\
\hline & SGA & $8(33.33 \%)$ & $30(13.89 \%)$ & 38 & \\
\hline \multirow{2}{*}{ Prematurity } & No & $15(71.43 \%)$ & $190(88.79 \%)$ & 205 & \multirow{2}{*}{0.023} \\
\hline & Yes & $6(28.57 \%)$ & $24(11.21 \%)$ & 30 & \\
\hline \multirow{2}{*}{ NICU admission/indication/duration of stay } & No & $12(57.14 \%)$ & $171(79.91 \%)$ & 183 & \multirow{2}{*}{0.016} \\
\hline & Yes & $9(42.86 \%)$ & $43(20.09 \%)$ & 52 & \\
\hline
\end{tabular}


The mean age of the study population was 27 years. It ranges from 20 to 35 years with a maximum study subject in the age group of 26 to 30 years. The youngest study subject was 20 years old and the oldest was 35 years of age (Table 1).

In the study population, median BMI was $23.56 \mathrm{~kg} / \mathrm{m}^{2}$ with minimum BMI-18.2 and maximum $35.15 \mathrm{~kg} / \mathrm{m}^{2}$. The median PAPP-A level of the study population was $1.01 \mathrm{MoM}$ with a minimum of $0.02 \mathrm{MoM}$ to Max of 3.24 MoM.
There were $50.83 \%$ pregnant women who were primigravida and $49.17 \%$ were multigravida.

PIH, pre-term labor and emergency LSCS were significantly associated with low $(<0.5 \mathrm{MoM})$ Serum PAPP-A levels, $\mathrm{p}<0.05$ (Table 2).

Fetal outcome measures: IUD, low birth weight, SGA babies, prematurity and NICU admissions, were significantly associated with low $(<0.5 \mathrm{MoM})$ serum PAPP-A levels, $\mathrm{p}<0.05$ (Table 3).

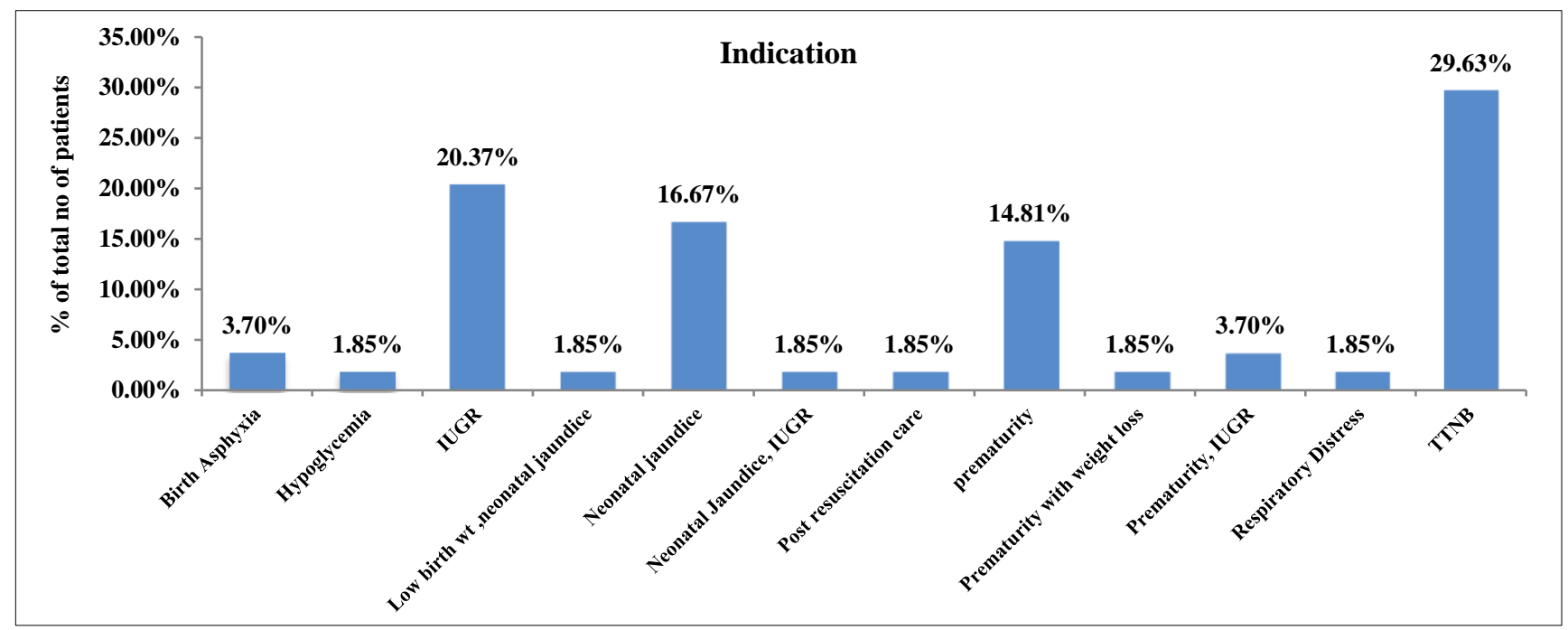

TTNB: Transitory tachypnea of newborn, IUGR: Intra-uterine growth retardation

Figure 1: Indications of NICU admission.

In this study, transitory tachypnea of new-born was the most common indication of NICU admission followed by growth retardation and neonatal jaundice (Figure 1).

\section{DISCUSSION}

Antenatal care universally aims for a healthy mother with a healthy newborn. But pregnancy carries considerable risk to both mother and fetus in due course of these 280 days long journey. So, the primary objective of prenatal care is to detect women at high risk of developing complications later in pregnancy, preferably in the first trimester for early preventive intervention.

PAPP-A can serve as a predictor for detecting women with adverse pregnancy outcomes. Several studies have reported the ethnicity of the study population influencing the level of PAPP-A biochemical marker. Krantz et al, suggested that all ethnic groups should have their reference range for PAPP-A levels in pregnancy, Leuwan $\mathrm{S}$ established a cut off range of PAPP-A and adverse outcomes associated with them in Thai population. ${ }^{6,7}$ There were limited studies for assessing the effect of serum PAPP-A levels on the fetomaternal outcome for the Indian population. In the current study, efforts were made to assess various outcomes at different thresholds of PAPP-A among the Indian population. The objective was to assess fetomaternal outcomes at various levels of serum PAPP-A, that is, less than $10 \%$ centile $(<0.5$ $\mathrm{MoM})$, and more than or equal to $10 \%$ centile $(>0.5$ MoM).

Most of the studies have taken a single parameter for evaluating the role of PAPP-A in fetomaternal outcome. In the present study, multiple parameters were evaluated concerning different PAPP-A levels.

Among the study population $(n=240)$ it was observed that significant adverse fetomaternal outcome was seen in $164(68.33 \%)$ pregnant woman. 3 out of 4 intrauterine deaths occurred in $<0.5 \mathrm{MoM}$ group. On further analysis, $<0.5$ MoM PAPP-A level was a strong predictor for LBW (50\%), PIH (33\%), and preterm birth (16.67\%).

A low level of PAPP-A causes abnormal placentation which is a proven etiopathogenesis of PIH, IUGR and in extreme cases IUD. PAPP-A is secreted from trophoblastic septal $\mathrm{X}$ cells, which causes the proteolysis of IGFBP-4 in placental bed at the fetomaternal interface to release IGF- $1 .^{8}$ IGF causes trophoblastic invasion into 
maternal decidua for the establishment and early development of the placenta and its vasculature. Distribution of adverse outcomes with various levels of PAPP-A, clearly indicates the inverse relation of serum PAPP-A at $1^{\text {st }}$ trimester. The current study supports that the lower value of PAPP-A that is $<0.5 \mathrm{MoM}(<10 \%$ centile) is associated with increased risk of IUD, PIH, preterm labor, emergency LSCS, SGA, prematurity, and NICU admission.

In the present study, the incidence of PIH was more in women with PAPP-A level less than $0.5 \mathrm{MoM}$ as compared to other groups. Similar results were concluded by Gorden $\mathrm{C}$ et al; that low PAPP-A levels were associated with increased risk of PIH $(7.6 \%$ versus $3.5 \%) .{ }^{9}$ The study conducted by Yarou et al, showed that low PAPP-A $(<0.25 \mathrm{MoM})$ levels are predictive for preeclampsia with a relative risk of $6.09 .{ }^{10}$ In another study conducted by Kaijomaa $\mathrm{M}$ et al, there was an increased incidence of $\mathrm{PIH}$ in the study group $(<0.3 \mathrm{MOM})$ compared to the control group (0.9 - $1.1 \mathrm{MOM})(4.7 \%$ versus $2.5 \%) .{ }^{11}$ Weaver A et al, reported that low PAPP$\mathrm{A}(\leq 0.3 \mathrm{MOM})$ is associated with a higher incidence of PIH. ${ }^{12}$ The difference in statistical analysis between the current study and other studies can be due to different cut off ranges in various studies. Contrary to above findings Saruhan $\mathrm{Z}$ et al, calculated $5^{\text {th }}$ and $10^{\text {th }}$ centile of PAPP-A levels with no significant relation was between low PAPP-A values and fetomaternal outcome such as PIH, IUGR, SGA, preterm delivery, increase rate of emergency LSCS. $^{13}$ They could not furnish any explanation for the same and attributed it to retrospective small size study along with the genetic background of population. $^{7}$

The burden of IUGR is concentrated mainly in developing countries especially in Asia which accounts for nearly $75 \%$ of all affected infants. In India, the prevalence of LBW has been reported as $26 \%$ and IUGR $14.56 \%$. This was in consensus with the present study where the Incidence of IUGR was $13.75 \%$ (33/240). Low PAPP-A group (<0.5 MoM) had only $3 / 33$ patients who developed IUGR. On summing the $<0.5 \mathrm{MoM}$ and 0.5-1 MoM groups, 25/33 patients developed IUGR. $75.75 \%$ of women could have been predicted with 1 MoM as PAPPA cut-off. With timely intervention, this problem could have been reduced. According to Saruhan Z et al, PAPP$A$ is not the only factor that controls IUGR as higher levels of PAPP-A could be expected in cases of macrosomia. ${ }^{13}$ On the other hand, many studies have reported that a low level of serum PAPP-A was responsible for abnormal placentation and vascularization which causes reduced growth of the fetus. Vandenberghe $\mathrm{G}$ et al concluded that PAPP-A MoM was significantly lower than control $(\mathrm{p}=0.003)$ in a growth-restricted fetus. ${ }^{14}$ Montanari L et al, reported that low serum PAPPA levels $(<10 \%$ centile) were associated with increased risk of IUGR due to placental dysfunction with OR of 3.9 (11\% versus $8 \%) .{ }^{15}$ According to Lau $\mathrm{H}$ et al, PAPP-A can be a useful tool to screen for impaired placentation associated with IUGR, as PAPP-A levels $(<0.45 \mathrm{MOM})$ $<1^{\text {st }}$ percentile had a PPV value for IUGR $(15 \%$ versus $2.8 \%) .{ }^{16}$ The discrepancy in the current study and other studies can be explained based on ethnicity, geographical distribution, the genetic potential of the population, small sample size of the study and other confounding factors not included in this study.

New-born babies born to women with low PAPP-A $(<0.5$ MOM), more incidence $(33.33 \%)$ of SGA was noted. Montanari L et al, also reported that the prevalence of SGA was significantly higher (17\% versus $8 \%$ ) among women with serum PAPP-A level below $10 \%$ centile compared to those with levels $>10^{\text {th }}$ centile. ${ }^{16}$ According to Spencer $\mathrm{K}$ et al, detection rates of SGA were $12 \%$, $14 \%$ and $16 \%$ with PAPP-A level below $10^{\text {th }}, 5^{\text {th }}$ and $3^{\text {rd }}$ centile of normal respectively. ${ }^{17}$ Kirkiguard I et al, predicted the strong association between PAPP-A $<0.3$ MoM and SGA (Odds Ratio 3.0). ${ }^{18}$ Serum PAPP-A promotes the proteolysis of IGFBP and releases IGF, regulates steroidogenesis and causes transport of glucose and amino acids in villus at materno-fetal interface hence low levels of PAPP-A decreases the growth of the fetus. Contrary to the majority in agreement to the present study, Saruhan $\mathrm{Z}$ et al, did not observe any association between PAPP-A levels and SGA. ${ }^{13}$ They reasoned it with the fact that the study had a retrospective design and had a small sample size.

In the present study, 16/24 (66.67\%) subjects with PAPPA $<0.5$ MoM had babies with birth weight less than 2.5 $\mathrm{kg}$. This can be explained by abnormal placentation as discussed above. Kaijomaa $M$ et al, also found a significant difference in the birth weight of Low PAPPA cohort and normal PAPP-A cohort $(3121 \pm 720.5 \mathrm{~g}$ versus $3511 \pm 572.3 \mathrm{~g} ; \mathrm{p}=<0.001){ }^{19}$

Out of the total study population, 5.83\% (14 out of 240) subjects developed preterm labor. Women with PAPP-A level $<0.5$ MoM had highest incidence of preterm labor i.e. $28.5 \%(4 / 14)(p=0.006)$. Every $4^{\text {th }}$ pregnant woman with low PAPP-A $(<0.5 \mathrm{MoM})$ is most likely to have preterm delivery. Many studies postulated that lower the concentration of PAPP-A in $1^{\text {st }}$ trimester, more the likelihood of preterm labor in women. This was evident in the present study also. Similar results were reported by Gordon $\mathrm{C}$ et al, (10\%) deriving association between extreme premature delivery and lowest centile of PAPPA. ${ }^{9}$ Goetzinger et al, stated that the risk of preterm delivery $(<35$ weeks) increased with $<10 \%$ centile of PAPP-A. ${ }^{19}$ Dane B et al, established an association of low PAPP-A levels ( $<0.35 \mathrm{MoM},<5 \%$ centile) with early preterm labor. ${ }^{20}$ According to Jelliffe-Pawlowski L et al, early preterm labor was associated with PAPP-A level $<5 \%$ centile. $^{2}$ It has been shown that IGF-1 is the key factor for autocrine and paracrine control of trophoblastic invasion into the decidua and IGF is regulated by PAPPA protein, this abnormal trophoblastic invasion leads to poor placentation and further development of preterm labor. Contrary to the above studies, Montanari L et al, 
could not demonstrate a significant association between PAPP-A values and preterm delivery $(6.3 \%$ of pregnant women). ${ }^{15}$ This could be due to the small sample size of the study. Various levels of PAPP-A were studied for their correlation with preterm labor.

In current study, $12.5 \%$ subjects in $<0.5$ MoM group had stillbirth while only $0.8 \%$ subjects with $>1.0$ MoM. It indicates that the risk of IUD increased to more than 15 times as the value of PAPP-A levels lowers down from $>1 \mathrm{MoM}$ to $<0.5 \mathrm{MoM}$. This can be attributed to preterm birth as 3 preterms (weight $462 \mathrm{~g}, 700 \mathrm{~g}$, and $1.4 \mathrm{~kg}$ ) IUD were recorded with PAPP-A level $<0.5 \mathrm{MoM}$. One full term sudden IUD $(2.4 \mathrm{~kg})$ was noted with PAPP-A level $>1$ MoM, where the cause could not be established. Similarly, Gorden CS et al, reported that $0.9 \%$ pregnant women in the study group $(<5 \%$ centile) had stillbirths compared to $>5 \%$ centile. ${ }^{9}$ Patil $\mathrm{M}$ et al, observed no stillbirth in subjects with normal PAPP-A levels while only one stillbirth reported out of 72 study subjects with PAPP-A levels <0.5 MoM. ${ }^{22}$ In Kaijomaa M, who studied 961 pregnant women with low $(<0.3$ MoM) PAPP-A levels, $9(0.9 \%)$ pregnancy resulting in stillbirth were observed in this group compared to normal population group (0.9-1.1 MoM).

The total number of GDM cases in the current study was $21(8.75 \%)$ which was not comparable with a prevalence of GDM in Asia (5-8\%) including India. ${ }^{23}$ The highest percentage of GDM was seen in PAPP-A >1 MOM i.e $12.30 \%$ as compared to PAPP-A levels $<0.5$ MOM i.e $4.17 \%$ and $0.5-1$ MOM i.e. $5.32 \%$ which was not statistically significant $(\mathrm{p}=0.14)$. Similarly, Cheuk QK et al did not observe any difference in $1^{\text {st }}$-trimester serum PAPP-A levels in women with or without GDM. ${ }^{24}$ According to Savvidou MD et al, median PAPP-A was reduced only in type 2 diabetes and there were no significant differences in maternal PAPP-A between GDM and type 2DM. ${ }^{25}$ According to Saruhaan $\mathrm{Z}$ et al, no significant association $(\mathrm{p}=0.99)$ was determined between GDM and PAPP-A levels $<10 \%$ centile ( $2.9 \%$ ) and $>10 \%$ centile $(4.9 \%) .{ }^{13}$ In the Indian scenario, we cannot give importance to PAPP-A levels and predict GDM in later pregnancy. India being capital of diabetes, one step and two-step glucose challenge test as per ACOG and FOGSI guidelines is mandatory in high-risk population and diabetes mellitus were included in the exclusion criteria of the study. Depending on the presence or absence of risk factors in the first visit and $2^{\text {nd }}$ trimester, the patient should be screened for diabetes. Large studies are required to develop a correlation between GDM and $1^{\text {st }}$-trimester serum PAPP-A levels.

No association of PAPP-A levels and second-trimester abortion could be established in this study. In contrast, other studies demonstrated a positive correlation between low PAPP-A levels and abortion. According to Gupta S et al, 148/1640 women had PAPP-A values <0.4 MoM. ${ }^{26}$ Out of which $18(12 \%)$ women had spontaneous/missed abortion. According to Lau H et al, PAPP- A <0.29 MoM can be a useful tool to screen for impaired placentation and a significantly higher ratio of spontaneous fetal loss $\leq 24$ weeks. ${ }^{16}$

The main limitations of the study were small sample size and the lack of the genetic analysis of the patients and the family.

\section{CONCLUSION}

It was concluded that PAPP-A can assess adverse maternal and fetal outcomes. Thus, it has the potential to be used as a prognostic factor in the management of adverse outcomes by increasing surveillance for pregnant women with high-risk factors.

Funding: No funding sources

Conflict of interest: None declared

Ethical approval: The study was approved by the Institutional Ethics Committee

\section{REFERENCES}

1. Lawrence BJ, Oxvig C, Overgaard MJ, SottrupJensen L, Gleich GJ, Hays LG, et al. The insulin-like growth factor (IGF)-dependent IGF binding protein4 protease secreted by human fibroblasts is pregnancy-associated plasma protein. Proc Natl Acad Sci USA. 1999;96(6):3149-53.

2. Malik J, Rai P, Das A, Das S. Pregnancy-associated plasma protein A - a level in first trimester and its impact on pregnancy outcome. Int $\mathrm{J}$ Contracept Obstet Gynecol. 2016;5(8):2680-3.

3. Gentile M, Schifano M, Lunardi S, Nanini C, Moscuzza F, Sergiampietri C, et al. Maternal PAPPA levels at 11-13 weeks of gestation predict foetal and neonatal growth-PAPP-A growth predictor. Open J of Obstet Gynecol. 2015;5:365-72.

4. Morris RK, Bilagi A, Devani P, Kilby MD. Association of serum PAPP-A levels in first trimester with small for gestational age and adverse pregnancy outcomes: systematic review and metaanalysis. Prenat Diagn. 2017;37(3):253-65.

5. Messerlian GL, Palomaki GE, Canick JA. Examination of the pregnancy-associated plasma protein-a assay on the beckman coulter access platform; suitability for use in first trimester Down's syndrome screening. J Med Screen. 2010;17:109-13.

6. Krantz D, Goetzl L, Simpson JL, Thom E, Zachary J, Hallahan TW, et al. Association of extreme first trimester free human chorionic gonadotropin/beta, pregnancy associated plasma protein $\mathrm{A}$ and nuchal translucency with intrauterine growth restriction and other adverse pregnancy outcomes. Am J Obstet Gynecol. 2004;191(4):1452-8.

7. Luewan S, Teja-intra M, Sirichotiyakul S, Tongsong T. Low maternal serum pregnancy associated plasma protein A as a risk factor for preeclampsia. Singapore Med J. 2018;59(1):55-9. 
8. Sinosich MJ. Biological role of pregnancy-associated plasma protein A in human reproduction. In: Bischof P, Klooper A (Eds): Proteins of the Placenta. $5^{\text {th }}$ International Congress on Placental Proteins, Annecy; 1984:158-183.

9. Smith GC, Stenhouse EJ, Crossley JA, Aitken DA, Cameron AD, Connor JM. Early pregnancy levels of pregnancy-associated plasma protein a and the risk of intrauterine growth restriction, premature birth, preeclampsia, and stillbirth. The J Clin Endocrinol Metab. 2002;87(4):1762-7.

10. Yaron Y, Heifetz S, Ochshorn Y, Lehavi O, OrrUrtreger A. Decreased first trimester PAPP-A is a predictor of adverse pregnancy outcome. Prenat Diagn. 2002;22(9):778-82.

11. Kaijomaa MK, Rahkonen L, Ulander VM, Hamalainen E, Alfthan H, Markkanen H, et al. Low maternal pregnancy associated plasma protein A during the first trimester of pregnancy and pregnancy outcomes. Int J Gynecol Obstet. 2017;136:76-82.

12. Weaver A, Nanda S, Rozette C, Kyle P, Sankaran S. Low maternal serum PAPP-A in the first trimester and pregnancy outcome: an experience over 3 years. Arch Dis Child Fetal Neonatal. 2013;98:A1-A112.

13. Saruhan Z, Ozekinci M, Simsek M, Mendilcioglu I. Association of first trimester low PAPP-A levels with adverse pregnancy outcomes. Clin Exp Obstet Gynecol. 2012;39(2):225-8.

14. Vandenberghe G, Mensink I, Twisk JW, Blankenstein MA, Heijboer AC, Vanvugt JM. First trimestor screening for intrauterine growth restriction and early onset preclampsia. Prenat Diagn. 2011;31(10):955-61.

15. Montanari L, Alfei A, Albonico G, Moratti R, Arossa A, Beneventi F, et al. The impact of firsttrimester serum free beta-human chorionic gonadotropin and pregnancy-associated plasma protein A on the diagnosis of fetal growth restriction and small for gestational age infant. Fetal Diagn Ther. 2009;25(1):130-5.

16. Lau H, Amarasekara C, Uppal T. Low PAPP-A: what are the clinical implications? Australas J Ultrasound Med. 2012;15(1):26-8.

17. Spencer K, Cowans NJ, Avgidou K, Molina F, Nicolaides H. First trimester biochemical markers of aneuploidy and the prediction of small-for gestational age fetuses. Ultrasound Obstet Gynecol. 2008;31:15-9.

18. Kirkiguard I, Henriksen TB, Uldberg N. Early fetal growth PAPP-A and free beta HCG in relation to risk of delivering a small for gestational age infant. Ultrasound Obstet Gynecol. 2011;37:341-7.

19. Goetzinger KR, Cahill AG, Macones GA, Odibo AO. Association of first-trimester low PAPP-A levels with preterm birth. Prenat Diagn. 2010;30(4):309-13.

20. Dane B, Dane C, Batmaz G, Ates S, Dansuk R. First trimester maternal serum pregnancy-associated plasma protein-A is a predictive factor for early preterm delivery in normotensive pregnancies. Gynecol Endocrinol. 2013;29(6):592-5.

21. Jelliffe-Pawlowski LL, Shaw GM, Currier RJ, Stevenson DK, Baer RJ, O'Brodovich HM, et al. Association of early-preterm birth with abnormal levels of routinely collected first- and secondtrimester biomarkers. Am J Obstet Gynecol. 2013;208(6):492.e1-11.

22. Patil M, Panchanadikar TM, Wagh G. Variation of PAPP-A level in the first trimester of pregnancy and its clinical outcome. J Obstet Gynaecol India. 2014;64(2):116-9.

23. Ashwani N, Rekha NA, Babu MS, Kumar CS, Pratap OT. Maternal risk factors associated with intrauterine growth restriction: hospital-based study. Int $\mathbf{J}$ Med Res Rev. 2016;4(12):2125-9.

24. Cheuk QK, Lo TK, Wong SF, Lee CP. Association between pregnancy-associated plasma protein-A levels in the first trimester and gestational diabetes mellitus in Chinese women. Hong Kong Med J. 2016;22(1):30-8.

25. Savvidou MD, Syngelaki A, Muhaisen M, Emelyanenko E, Nicolaides KH. First trimester maternal serum free b-human chorionic gonadotropin and pregnancy-associated plasma protein $\mathrm{A}$ in pregnancies complicated by diabetes mellitus. BJOG. 2012;119:410-6.

26. Gupta S, Goyal M, Verma D, Sharma A, Bhardwaj $\mathrm{N}$, Kabra M, et al. Adverse pregnancy outcome in patients with low pregnancy-associated plasma protein-A: The Indian Experience. J Obstet Gynaecol Res. 2015;41:1003-8.

Cite this article as: Singh S, Singh P. Effect of first trimester maternal serum pregnancy-associated plasma protein: a level on fetomaternal outcome. Int J Reprod Contracept Obstet Gynecol 2020;9:87-93. 